$1-2014$

\title{
Cultural determinants of status: Implications for workplace evaluations and behaviors
}

\author{
Carlos J. Torelli \\ Lisa M. Leslie \\ Jennifer L. Stoner \\ University of North Dakota, jennifer.stoner@UND.edu \\ Raquel Puente
}

How does access to this work benefit you? Let us know!

Follow this and additional works at: https://commons.und.edu/mark-fac

Part of the Organizational Behavior and Theory Commons

\section{Recommended Citation}

Carlos J. Torelli, Lisa M. Leslie, Jennifer L. Stoner, et al.. "Cultural determinants of status: Implications for workplace evaluations and behaviors" (2014). Marketing Faculty Publications. 1.

https://commons.und.edu/mark-fac/1

This Article is brought to you for free and open access by the Department of Marketing at UND Scholarly Commons. It has been accepted for inclusion in Marketing Faculty Publications by an authorized administrator of UND Scholarly Commons. For more information, please contact und.commons@library.und.edu. 


\begin{abstract}
Status is a valued workplace resource that facilitates career success, yet little is known regarding whether and how cultural orientation affects status attainment. We integrate status characteristics theory with the literature on individualism and collectivism and propose a cultural patterning in the determinants of status. Four studies $(N=379)$ demonstrate that cultural orientation influences the tendency to view high status individuals as competent versus warm (Study 1), uncover cultural differences in both individuals' tendency to engage in competence and warmth behaviors to attain workplace status (Study 2) and evaluators' tendency to ascribe status to individuals who demonstrate competence versus warmth (Study 3), and verify that cultural differences in the effects of competence and warmth on status perceptions, and in turn performance evaluations, generalize to real world interdependent groups (Study 4). Our findings advance theory on the cultural contingencies of status attainment and have implications for managing diversity at work.
\end{abstract}

Keywords: Status, Culture, Social hierarchy, Competence, Warmth, Individualism and collectivism, Status characteristics theory 


\section{Cultural Determinants of Status:}

\section{Implications for Workplace Evaluations and Behaviors}

From the standing of countries on a global scope to the arrangement of individuals according to their station in life, social hierarchy_-defined as "an implicit or explicit rank order of individuals or groups with respect to a valued social dimension” (Magee \& Galinsky, 2008, p. 354) — is so prevalent in human societies that it is a defining feature of social relations. Social hierarchy is not only a fundamental aspect of societies; it also serves two important functions in organizations and is therefore inherent to work settings. Specifically, social hierarchy facilitates the coordination of activities necessary to achieve organizational goals and incents employees to achieve high levels of performance as a mechanism for moving up in rank (cf. Deci \& Ryan, 1987; Durkheim, 1997; Magee \& Galinsky, 2008; Marx, 1964; McClelland, 1975; Tannenbaum, Kavcic, Rosner, Vianello, \& Wieser, 1974; Van de Ven, Delbecq, \& Koenig, 1976; Weber, 1946). Given the centrality of social hierarchy to the process of organizing, it is not surprising that a literature has emerged on the consequences of a primary dimension of social hierarchystatus - for a range of organizational phenomena, including team processes and outcomes, trust, communication, procedural fairness, workplace deviance, and exchange relationships, among others (e.g., Bowles \& Gelfand, 2010; Castellucci \& Ertug, 2010; Chen, Brockner, \& Greenberg, 2003; Christie \& Barling, 2010; Flynn, 2003; Fragale, 2006; Fragale, Rosen, Xu, \& Merideth, 2009; Lount \& Pettit, 2012; Perretti \& Negro, 2006).

Status, defined as the extent to which an actor is respected and highly regarded in the eyes of others (cf. Blau, 1964; Goldhamer \& Shils, 1930; Ridgeway \& Walker, 1995; Zelditch, 1968), is an important commodity inside and outside of organizations. People are concerned with achieving and maintaining status, which in turn has desirable consequences (e.g., Frank, 1985; 
Sutton \& Hargadon, 1996). Indeed, as compared to low status individuals, high status individuals are more likely to be trusted by and receive help from others (Lount \& Pettit, 2012; Van Der Vegt, Bunderson, \& Oosterhof, 2006), less likely to be negatively evaluated for deviant behavior (Bowles \& Gelfand, 2010), and more likely to receive inflated performance evaluations and to be given opportunities to succeed (Darley \& Gross, 1983; Magee \& Galinsky, 2008). It is therefore not surprising that the question of how individuals attain and maintain high status has been a topic of interest to scholars (e.g., Anderson \& Kilduff, 2009a, 2009b; Anderson, Spataro, \& Flynn, 2008; Berger, Rosenholtz, \& Zelditch, 1980). One robust conclusion within this literature is that perceived competence (i.e. agency, ability, efficacy, confidence) is a key determinant of status; competent individuals and groups achieve high status and, conversely, high status individuals and groups are also viewed as competent by others (e.g., Berger et al., 1980; Fiske, Cuddy, Glick, \& Xu, 2002; Magee \& Galinsky, 2008). Moreover, the link between competence and status has been replicated in many cultures, suggesting that this relationship may be pancultural (Cuddy, et al., 2009).

Nevertheless, there are several reasons to question the universality of status attainment (i.e. what type of individual comes to be viewed as high status by others). First, recent research shows that culturally-nurtured views of power-a related but distinct dimension of social hierarchy_vary significantly, such that power is viewed as a mechanism for advancing one's own interests among individuals with certain cultural orientations but as a mechanism for advancing the interests of others among individuals with other cultural orientations (Torelli \& Shavitt, 2010). Second, theories of status attainment suggest that the determinants of status are context-dependent and thus allow for the possibility of cultural contingencies. More specifically, a key tenet of status characteristics theory is that individuals attain high status if they possess 
characteristics that are valued in a given setting (i.e. status characteristics, e.g., Berger, et al., 1980). Perceived competence is a valued status characteristic in organizations and other taskoriented groups, yet decades of research demonstrate that valued social characteristics vary widely among individuals with different cultural orientations (e.g., Hofstede, 2001; House, Hanges, Javidan, Dorfman, \& Gupta, 2005). The robust linkage between competence and status is consistent with values and norms among those with an individualistic cultural orientation, who emphasize personal goals of achievement, success, and self-reliance (Triandis, 1995); however, those with a collectivistic cultural orientation emphasize sociability and interdependence (Triandis, 1995), which suggests that judgments regarding individuals’ generosity, kindness, and friendliness (i.e. interpersonal warmth) may also contribute to status judgments. We therefore integrate status characteristics theory with research on cultural differences in individualism and collectivism and propose that the tendency to view competence and warmth-the two fundamental dimensions of person perception (Asch, 1946; Cuddy, et al., 2009; Judd, JamesHawkins, Yzerbyt, \& Kashima, 2005; Wojciszke, Bazinska, \& Jaworski, 1998)—as determinants of status is a function of individuals' cultural orientation.

We investigate this proposition in four studies. We first demonstrate the basic phenomenon by showing that individualism is positively related to the tendency to perceive high status individuals as competent, whereas collectivism is positively related to the tendency to perceive high status individuals as warm (Study 1). We then investigate the relevance of cultural differences in status attainment for organizations by showing that cultural orientation is related to the behaviors individuals engage in to acquire status at work (Study 2) and the behaviors evaluators use to ascribe status to others (Study 3). Finally, we document that culture influences the association of competence and warmth with status in interdependent task groups, and that 
status has consequences for an important workplace outcome: appraisals of group members’

performance (Study 4). Across studies, we operationalize culture using two different measures of individual-level cultural orientation, as well as participants from cultural groups known to vary in their cultural orientation (Chiu \& Hong, 2006; Lehman, Chiu, \& Schaller, 2004), and thus provide strong support for a cultural patterning in the determinants of status. Collectively, these studies demonstrate that status attainment is not pancultural, but is sensitive to differences in individualism and collectivism. Our findings therefore have important implications for managing cultural diversity at work.

\section{Theory Development}

Status characteristics theory provides a useful framework for understanding status attainment in task-oriented groups - that is - why some group members earn respect and admiration in the eyes of other group members, but others do not (e.g., Berger, Cohen, \& Zelditch, 1972; Berger, et al., 1980; Webster \& Driskell, 1978). According to status characteristics theory, status attainment is driven by the extent to which group members are perceived to possess status characteristics, defined as traits that are valued in the setting because they are positively associated with expectations of future performance. Specifically, individuals expect that group members who possess valued status characteristics will achieve high performance in the future and therefore respect those group members and afford them positions of high status within the group. Alternatively, group members perceived to lack valued status characteristics are afforded positions of low status (Berger, et al., 1980).

In organizations and other task-oriented groups, competence (i.e. intelligence, agency, ambition) is considered critical for achieving strong performance. It is therefore not surprising that "the basis of respect in organizations is competence, or more precisely, judgments about a 
target individual’s competence” (Magee \& Galinsky, 2008, p. 373). Indeed, a large body of research demonstrates that perceived competence is a valued status characteristic. For example, the degree of competence demonstrated by an employee is positively associated with the degree of status ascribed to that employee by others (Sutton \& Hargadon, 1996) and, conversely, evaluators assume that individuals assigned to high status positions (e.g., managers) are more competent than individuals assigned to a low status position (e.g., clerks)—even when aware that position assignments are random (Humphrey, 1985; Sande, Ellard, \& Ross, 1986).

Research has focused on perceived competence as the key antecedent of status in organizations and other task-focused groups, yet status characteristics theory also allows for variation in the determinants of status. Specifically, status characteristics are characteristics that are valued in a given setting because they are positively associated with expectations of future performance. To the extent that valued characteristics vary across settings, there may also be variation in the determinants of status (cf. Anderson, et al., 2008; Berger, et al., 1980; Fragale, 2006). Consistent with this notion, there is some evidence that perceived warmth, like perceived competence, at times determines who attains status. For example, early research found that some members of problem-solving groups acquire status based on their task ability (i.e. competence), whereas others acquire status based on their socio-emotional ability (i.e. warmth) (e.g., Slater, 1955), and more recent evidence indicates that individuals at times engage in prosocial, helpingoriented behaviors that demonstrate warmth as a mechanism for achieving status (Flynn, Reagans, Amanatullah, \& Ames, 2006). In addition, one study provided insight into when competence versus warmth is a stronger determinant of status. Specifically, individuals who used speech styles that conveyed competence attained status when working on an individual task, but individuals who used speech styles that conveyed warmth attained status when working on an 
interdependent task (Fragale, 2006). This finding is consistent with status characteristics theory, which suggests that status characteristics (competence versus warmth) depend on what is valued in the setting (task type).

Prior theory substantiates that the determinants of status depend on task type, yet there is reason to believe that the characteristics associated with status are also a function of individuals’ cultural orientation, even among individuals working on the very same task. Specifically, abundant research substantiates that cultural orientation is a robust source of differences in valued social characteristics (e.g., Hofstede, 2001; House, et al., 2005). An integration of research on cultural orientation—and specifically on individualism and collectivism—with status characteristics theory therefore suggests that the determinants of status are culturally-contingent.

Individualism and collectivism are the two most widely studied dimensions of cultural variability in the values that societies, and in turn the individuals within those societies, deem important (Triandis, 1995). It stands to reason that these cultural dimensions should also affect the valued characteristics that determine status. In individualistic cultures, "ties between individuals are loose; everyone is expected to look after himself or herself and his or her immediate family” (Hofstede, 1980, p. 51). Individuals from individualistic cultures are therefore socialized to value individual goals, personal achievement, autonomy, and self-actualization (Hofstede, 2001; Triandis, 1995). These values are reflected in definitions of strong performance, which emphasize individuals' task accomplishments and bottom-line results (Alis, 1988; Ferris \& Tredaway, 2008; Stone, Stone-Romero, \& Lukaszewski, 2007). Because perceived competence reflects self-centered traits such as efficacy, confidence, and agency (Bakan, 1966), competence should be a valued characteristic that is positively associated with expectations of 
future performance, and thus constitute a source of status, among those with an individualistic cultural orientation.

Alternatively, in collectivistic cultures, "people from birth onward are integrated into strong, cohesive in-groups, which throughout people’s lifetime continue to protect them in exchange for unquestioning loyalty” (Hofstede, 1980, p. 51). Individuals from collectivistic cultures are therefore socialized to value group goals and loyalty, interdependence, and sociability (Hofstede, 2001; Triandis, 1995). These values are reflected in definitions of strong performance, which emphasize integrity, interpersonal relationships, and citizenship (Alis, 1988; Ferris \& Tredaway, 2008; Stone, et al., 2007). Because perceived warmth reflects other-centered traits such as generosity, kindness, friendliness, and communion (Bakan, 1966), warmth should be a valued characteristic that is positively associated with expectations of future performance, and thus constitute a source of status, among those with a collectivistic cultural orientation.

The above logic suggests that competence is associated with status among individualists and warmth is associated with status among collectivists. At the same time, individual achievement is a universally desirable trait (Schwartz, 1990), particularly in work settings where personal achievement and task accomplishment are vital for organizational success (Magee \& Galinsky, 2008). Moreover, evidence indicates that the competence-status linkage emerges in both individualistic and collectivistic cultures (e.g., Cuddy, et al., 2009). Thus, we do not propose that the competence-status linkage is unique to individualistic cultures. Rather, we conceptualize individualism and collectivism as distinct continuous dimensions (cf. Oyserman, Coon, \& Kemmelmeier, 2002; Triandis \& Gelfand, 1998) and propose that the association between competence and status is stronger for individuals higher (versus lower) on 
individualism. Likewise, we propose that the association between warmth and status is stronger for individuals higher (versus lower) on collectivism. We test these propositions in four studies.

\section{Study 1}

In Study 1, we investigate the extent to which individuals perceive high status individuals as warm and competent, as a function of their cultural orientation. Consistent with our general propositions, we expect that the extent to which individuals have an individualistic cultural orientation will be positively associated with perceptions of high status individuals as competent, whereas the extent to which individuals have a collectivistic cultural orientation will be positively associated with perceptions of high status individuals as warm. Membership in different cultural groups (e.g., societies or countries) is a powerful source of individual differences in cultural orientation; however, evidence demonstrates that individuals also differ in their cultural orientation within cultural groups, including the U.S. (Vandello \& Cohen, 1999). For example, within-country variation in individualism and collectivism can be driven by ecological (e.g., collectivistic farming practices in the Deep South of the U.S.), historical (e.g., the prominence of religion in the Deep South of the U.S.), and migratory (e.g., more collectivistic Mexican and Spanish settlers in the South West of the U.S.) factors (Vandello \& Cohen, 1999). In Study 1, we therefore recruit participants in the U.S. and operationalize culture using variation in individual-level cultural orientation (cf. Chiu \& Hong, 2006; Lalwani, Shrum, \& Chiu, 2009; Torelli \& Shavitt, 2010).

Hypothesis 1: Individuals higher on individualism will perceive high status individuals as higher in competence than individuals lower on individualism.

Hypothesis 2: Individuals higher on collectivism will perceive high status individuals as higher in warmth than individuals lower on collectivism. 


\section{Method}

Eighty-nine participants took part in the study, who were recruited using Amazon’s Mechanical Turk (MTurk) (mean age = 33.7 years, 36\% male, 57\% Caucasian) and were paid the equivalent of $\$ 2 .{ }^{1}$ Following procedures adopted in past research (Torelli \& Shavitt, 2008), participants were asked to think about high-status individuals (i.e. persons with high status, that is, people respected, admired, and highly regarded by others) that were familiar to them, and to use six-point scales $(1=$ Not at all, $6=$ Very much $)$ to collectively rate these individuals in terms of their competence (ambitious, energetic, conscientious, creative, and intelligent; $\alpha=.73$ ) and warmth (caring, friendly, generous, sociable, and openhearted; $\alpha=$.87) (Fiske, et al., 2002). After completing several filler tasks, participants completed a 16-item measure of individualism (IND) and collectivism (COL; 1 = strongly disagree, 7 = strongly agree) (Triandis \& Gelfand, 1998). ${ }^{2}$ Example items include: “I'd rather depend on myself than others" and "Winning is everything” for IND ( $\alpha=.68)$; and "I feel good when I cooperate with others" and "It is important to me that I respect the decision made by my group” for COL $(\alpha=.81)$. Finally, participants answered demographic questions and were debriefed.

\section{Results and Discussion}

Scale structure. We used confirmatory factor analysis (CFA) to assess the structure of the study variables (competence, warmth, IND, COL). We fit the data to a four-factor model and found a reasonable fit $(\mathrm{CFI}=.90$, RMSEA $=.06)$, which in turn was better than the fit of a

\footnotetext{
${ }^{1}$ Evidence indicates that data collected from MTurk is as reliable as data collected from more traditional samples (Buhrmester, Kwang, \& Gosling, 2011).

${ }^{2}$ The IND/COL scale includes horizontal (H) and vertical (V) sub-dimensions of IND and COL; however, when V/H distinctions are not of theoretical interest (as in our case), collapsing items into a single IND scale and a single COL scale offers reliable measures that have been widely used in past research (cf. Heinke \& Louis, 2009; Lalwani, 2009; Ozdemir \& Hewett, 2010). In all studies using this scale, we assessed the structural soundness of the scale using second order CFAs (IND and COL as higher-order factors), and determined that this model offered a better fit to the data $\left(\Delta \chi^{2}=12-57 ; \Delta \mathrm{CFI}=.05-.10\right)$ than a model including $\mathrm{H}$ and $\mathrm{V}$ as higher-order factors, or a model with four separate inter-correlated factors (HI, VI, HC, VC; no second-order factor). We therefore computed IND and COL scores by averaging across the V/H sub-scales.
} 
single-factor model (CFI $=.42$, RMSEA $\left.=.14, \Delta \chi^{2}=1,065, p<.01\right)$. Correlations among the study variables appear in Table 1.

Hypothesis testing. The zero-order correlations in Table 1 provide initial support for Hypotheses 1 and 2; IND was positively correlated with the perceived competence $(r=.24, p<$ .03), but not warmth $(r=.12, n s)$, of high-status individuals, whereas COL was positively correlated with the perceived warmth $(r=.36, p<.01)$, but not competence $(r=.17$, ns), of high status individuals. To test these hypotheses while accounting for correlation between competence and warmth $(r=.52)$, we used the software provided by Bentler (1995) to estimate a structural equation model with competence $\left(R^{2}=.14\right)$ and warmth $\left(R^{2}=.19\right)$ as the dependent variables, IND and COL scores as predictors, and age, ethnicity (dummy coded, 1 = Caucasians) and gender (dummy coded, 1 = male) as covariates (see Figure 1). We accounted for the correlation between competence and warmth in this model by allowing the residuals to covary. In support of Hypothesis 1, there was a significant positive relationship between IND and the perceived competence of high-status individuals $(b=.29, p<.05)$. In support of Hypothesis 2 , there was a significant positive relationship between COL and the perceived warmth of high-status individuals $(b=.36, p<.05)$. In contrast, relationships between COL and competence $(b=.18$, $n s)$ and IND and warmth $(b=.17, n s)$ were not significant. None of the covariates were significantly related to either competence or warmth $(b=-.11-.18, n s)$

[Insert Table 1 \& Figure 1 about here]

Discussion. The Study 1 results support the proposed cultural patterning in the traits ascribed to high-status individuals. Individualism was positively related to the tendency to associate competence with high-status individuals, whereas collectivism was positively related to the tendency to associate warmth with high-status individuals. 
We operationalized culture as individual-level cultural orientation within a single culture (the U.S.) and correlated cultural orientation with competence and warmth. This correlational approach is common in cross-cultural research (cf. Chiu \& Hong, 2006; Lalwani, et al., 2009; Torelli \& Shavitt, 2010) and the use of individual-level cultural orientation is consistent with evidence that cultural orientation varies significantly within cultures (Vandello \& Cohen, 1999). Nevertheless, to provide evidence for the robustness of the effects, in Study 2 we operationalize culture using participants from cultural groups known to vary in individualism and collectivism (U.S. Americans of European descent and Latin Americans). This approach also offers an important advantage over the correlational design in Study 1. Specifically, we measured cultural orientation after competence and warmth in Study 1 and it is therefore possible that, contrary to our theory, competence and warmth had a causal effect on cultural orientation. Alternatively, because it is not possible for participants' survey responses to have a causal impact on the cultural group to which they belong, Study 2's design rules out the possibility of reverse causation. Finally, Study 2 builds on Study 1 by demonstrating that the proposed cultural patterning in the traits associated with status has implications for workplace behavior.

\section{Study 2}

Culture consists of shared meanings that provide a common frame of reference for a human group to make sense of reality, coordinate their activities, and adapt to their environment (Shore, 2002; Sperber, 1996). Once individuals internalize a given cultural orientation, they use that cultural orientation to organize their experiences and guide their life practices (Chiu \& Hong, 2006). If cultural patterns exist in the traits associated with status, individuals should behave in ways that express these traits in contexts where achieving status is important. We test this notion by measuring individuals’ self-reports of engaging in behaviors associated with 
competence and warmth to attain status at work. Consistent with our general propositions, we expect that individualism will be associated with seeking status by demonstrating competence, whereas collectivism will be associated with seeking status by demonstrating warmth. In Study 2, we also seek further support for a cultural patterning in the determinants of status by comparing individuals in a culture known to be high on individualism and low on collectivism (the U.S.) to individuals in a culture known to be low on individualism and high on collectivism (Latin Americans; Triandis, 1995).

Hypothesis 3: Individuals higher on individualism (U.S. Americans) are more likely to seek status by engaging in behaviors that signal competence than individuals lower on individualism (Latin Americans).

Hypothesis 4: Individuals higher on collectivism (Latin Americans) are more likely to seek status by engaging in behaviors that signal warmth than individuals lower on collectivism (U.S. Americans).

\section{Method}

The sample for Study 2 included 164 individuals from two cultural groups. The first group comprised 63 U.S. Americans, all of whom were of European descent, recruited both using Amazon’s Mechanical Turk (MTurk) $\left(N_{1}=43\right.$, mean age $=39.5$ years, mean working experience $=16.3$ years, $37 \%$ male, $76 \%$ with college degree) and by surveying graduate business students at a public Midwestern university $\left(N_{2}=20\right.$, mean age $=38.9$ years, mean working experience $=15.8$ years, $45 \%$ male, $100 \%$ with college degree). The second group consisted of 101 Latin American participants, recruited both using Amazon’s Mechanical Turk $($ MTurk $)\left(N_{3}=42\right.$, mean age $=35.7$ years, mean working experience $=12.7$ years, $31 \%$ male, 79\% with college degree, $83 \%$ born in Central and South America) and by surveying graduate 
business students from a private Colombian (South American) university $\left(N_{4}=59\right.$, mean age $=$ 33.0 years, mean working experience $=11.2$ years, $54 \%$ male, $100 \%$ with college degree).

Participants were asked to think about jobs they have held and to remember the different types of behaviors they enacted to attain status (i.e. "to gain respect and admiration and to be highly regarded by their supervisor”). They were then asked to indicate how frequently they engaged in a series of eight behaviors that were interspersed among filler behaviors using a seven-point scale ( 1 = Almost never, 7 = Very frequently). The behaviors scale was developed based on past research (Fiske, et al., 2002) and included four behaviors associated with warmth ("Volunteer outside your working hours to help your co-workers with their personal issues," "Use your personal time to help a coworker outside of working hours," "Congratulate the winner of 'best office employee' award," and "Stay late at an office party even when you think everyone is pretty shallow;" $\alpha=.77$ ) and four behaviors associated with competence ("Work late to be sure you did the best job possible on a work assignment," "Display awards you have won for your task accomplishments on your desk so your supervisor will see them," "Work to solve a tough problem at work even though you were not expected to," and "Make sure that you appear secure and able to answer questions in a coherent way when called upon by your boss;” $\alpha=.68$ ).

After a series of filler tasks that took 15 minutes to complete, participants completed several manipulation checks. At the country-level of analysis, the U.S. and Latin America differ in individualism and collectivism; however, given that our focus is individual-level cultural orientation, it was important to verify that the specific individuals in our sample varied as expected in cultural orientation. Participants therefore completed the same IND/COL scale used in Study 1 (IND: $\alpha=.70$; COL: $\alpha=.81$ ). They also rated the competence and warmth behavioral items in terms of the extent to which they signal competence ("To what extent does this behavior 
symbolize competence. That is, to what extent does enacting this behavior suggest that one is competent, capable and intelligent?") and warmth (“To what extent does this behavior symbolize warmth. That is, to what extent does enacting this behavior suggest that one is interpersonally warm, good natured, and sincere?”), using a response scale that ranged from “ 1 = Not at all” to “7 = A great deal.” ${ }^{3}$ Finally, participants answered demographic questions and were debriefed. U.S. participants completed the questionnaire in English, whereas Latin American participants completed it in Spanish. Translation was done using standard back-translation procedures (Brislin, 1970).

\section{Results and Discussion}

Manipulation checks. We assessed whether participants differed as expected in IND and COL. Two ANOVAs revealed that, as expected, and regardless of the sample (MTurk participants or graduate students), U.S. Americans reported higher IND than Latin Americans $\left(M_{\text {U.S.Americans }}=5.06\right.$ and $\left.M_{\text {Latin Americans }} 4.70, F(1,160)=6.37, p<.02\right)$, whereas the opposite was

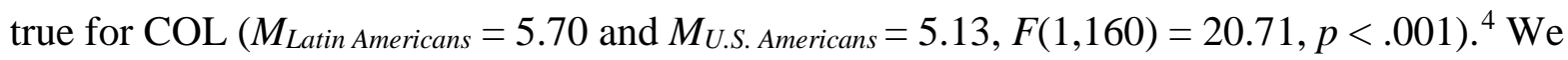
also analyzed the extent to which participants indicated that the competence- and warmth-related behaviors signaled competence and warmth. Participants rated each of the competence behaviors as more indicative of competence than of warmth (all $t \mathrm{~s}>5.48$, all $p \mathrm{~s}<.001, M_{\text {competence }}=4.89$

\footnotetext{
${ }^{3}$ In addition to asking the participants to indicate the extent to which the behavioral items signaled competence and warmth, we further validated this scale by asking a separate group of participants recruited through Mturk $(N=34)$ to use the same scales to rate the behavioral items. Participants indicated that each of the competence items signaled competence more than warmth (all ts(33) $>3.91$, all $p$ s $<.001, M_{\text {competence }}=5.11$ and $M_{\text {warmth }}=3.54$ ) and each of the warmth items signaled warmth more than competence (all ts(33) $>2.83$, all $p \mathrm{~s}<.01, M_{\text {warmth }}=5.77$ and $M_{\text {competence }}=$ 4.44).

${ }^{4}$ The between-cultural group differences in IND and COL scores in our samples were consistent with expectations about the different cultural groups reported in past research (e.g., Hofstede, 1980, 2001), the within-cultural group differences in IND and COL scores did not follow the same pattern. Although Latin Americans scored significantly higher in COL than they did in IND, U.S. participants scored similarly in IND and COL. This is not such a rare event in the literature (e.g., Chen, Brockner, \& Katz, 1998; Torelli \& Shavitt, 2010), as IND and COL orientations are separate dimensions that can manifest themselves in any given individual. Importantly, our operationalization of culture in this study focuses on the between-group differences in IND and COL, which behaved as expected.
} 
and $M_{\text {warmth }}=3.57$ ), and rated each of the warmth behaviors as more indicative of warmth than of competence (all ts $>7.08$, all $p s<.001, M_{\text {warmth }}=5.52$ and $M_{\text {competence }}=3.70$ ).

Scale structure. An exploratory factor analysis (EFA) of the eight behaviors yielded two factors that accounted for $52.6 \%$ of the variance. As expected, the competence and warmth behaviors loaded on separate factors (all factor loadings greater than .40 on the corresponding factor and lower than .30 on the other factor). A two factor CFA model (competence behaviors, warmth behaviors) also fit the data reasonably well (CFI $=.92$, RMSEA $=.05$ ), and significantly better than a single factor model (CFI $=.68$, RMSEA $\left.=.17, \Delta \chi^{2}=68.5, p<.01\right)$. Correlations among the Study 2 variables appear in Table 1.

Hypothesis testing. To test Hypotheses 3 and 4, we submitted the self-reports of behaviors associated with competence and warmth to a repeated measures ANOVA with cultural group (U.S. Americans or Latin Americans) and type of sample (MTurk participants or graduate students) as between-subjects factors and type of behavior (competence or warmth) as a withinsubjects factor, and demographic variables (age, gender, working experience, and education) as covariates (see Table 2). Results showed only a significant type of behavior by cultural group interaction, $F(1,156)=45.26, p<.001, \eta^{2}=.23$. Simple contrasts revealed that, in order to gain status in the workplace, U.S. Americans (higher IND; $M=5.05$ ) reported a higher frequency of enacting competence behaviors than Latin Americans (lower IND; $M=4.38$ ) did; $F(1,156)=$ 14.85, $p<.001, \eta^{2}=.09$ (see Figure 2), which supports Hypothesis 3. In contrast, and consistent with Hypothesis 4, Latin Americans (higher COL; $M=4.59$ ) reported a higher frequency of enacting warmth-related behaviors than U.S. Americans (lower COL; $M=3.73$ ) did, $F(1,156)=$ 13.49, $p<.001, \eta^{2}=.08$. Although not directly relevant to our hypotheses, additional simple contrasts revealed that U.S. Americans reported a higher frequency of engaging in competence 
behaviors than warmth behaviors, $F(1,156)=62.05, p<.001, \eta^{2}=.29$, whereas Latin Americans reported engaging in competence and warmth behaviors with equal frequency, $F(1,156)=2.91$, ns. Importantly, these patterns emerged regardless of the sample (MTurk participants or graduate students) as the type of sample did not moderate the type of behavior by cultural group interaction $(F=.01, n s$, see Table 2$)$.

[Insert Table 2 \& Figure 2 about here]

Discussion. Study 2 reveals a cultural patterning in the self-reported behaviors that employees enact to attain status at work. Individuals higher in individualism (U.S. Americans) were more likely to engage in competence-signaling behaviors to acquire workplace status than individuals lower in individualism (Latin Americans), whereas individuals higher in collectivism (Latin Americans) were more likely to engage in warmth-signaling behaviors to acquire workplace status than individuals lower in collectivism (U.S. Americans). These findings converge with Study 1 and were obtained using diverse samples (MTurk participants and business students) from cultural groups that differ in individualism and collectivism instead of an individual-level cultural orientation measure. Thus, Study 2 builds on Study 1 by ruling out common method variance and reverse-causality as alternative explanations and substantiating that the proposed cultural patterning in the determinants of status is robust to different operationalizations of culture. Study 2 also demonstrates the relevance of cultural differences in the determinants of status for self-reports of individuals’ workplace behaviors.

In addition to finding that individualism is positively associated with seeking status by engaging in competence behaviors and collectivism is positively associated with seeking status by engaging in warmth behaviors, Study 2 also indicates that individualists (U.S. Americans) are more likely to engage in competence than warmth behaviors whereas collectivists are equally 
likely to engage in competence and warmth behaviors. This suggests that competence is a more valued status characteristic than warmth among individualists, whereas competence and warmth are equally valued status characteristics among collectivists. Notably, this finding is consistent with the notion that personal achievement is valued in all cultures, whereas the promotion of smooth ingroup relations is more distinctively valued in collectivistic cultures (Schwartz, 1990), as well as with evidence that the competence-status link is pancultural (Cuddy et al., 2009).

In Study 3 we further investigate the consequences of a cultural pattern in the determinants of status by investigating whether culture influences the extent to which evaluators ascribe status to individuals who engage in workplace behaviors that demonstrate competence or warmth. Moreover, we seek further evidence that competence and warmth determine status by experimentally manipulating competence and warmth and measuring perceived status.

\section{Study 3}

Just as culture influences the behaviors individuals engage in to attain status at work, culture should also have consequences for the behaviors evaluators interpret as a signal of status. Consistent with our general propositions, we expect that the tendency to ascribe status to individuals who demonstrate competence in a work setting is stronger among evaluators who are higher (versus lower) on individualism, whereas the tendency to ascribe status to individuals who demonstrate warmth in a work setting is stronger among evaluators who are higher (versus lower) on collectivism.

Study 3 also builds on Studies 1 and 2, in which competence and warmth were not mutually exclusive, by pitting competence and warmth against each other. Specifically, we asked participants who varied in their cultural orientation to ascribe status to two individuals that differed in their performance of competence and warmth behaviors: one individual excelled on 
competence but not warmth, and one excelled on warmth but not competence. Our theory and prior findings indicate that individualism increases the competence-status link but is unrelated to the warmth-status link and that collectivism increases the warmth-status link but is unrelated to the competence-status link. It follows that, when ascribing status to others, evaluators higher (vs. lower) on individualism will be more sensitive to others’ competence. Thus, evaluators higher on individualism will ascribe more status to an exceptionally competent (but low warmth) individual than evaluators lower on individualism. In contrast, when ascribing status to others, evaluators higher (vs. lower) on collectivism will be more sensitive to others’ warmth. Thus, evaluators higher on collectivism will ascribe more status to an exceptionally warm (but low competence) individual than evaluators lower on collectivism.

Hypothesis 5: Evaluators higher on individualism will ascribe more status to an individual who excels on competence, but not warmth, than evaluators lower on individualism.

Hypothesis 6: Evaluators higher on collectivism will ascribe more status to an individual who excels on warmth, but not competence, than evaluators lower on collectivism.

\section{Method}

The sample included 58 college students from a large Midwestern university, who participated in the study in exchange for course credit (average age $=20.9$ years, $61 \%$ male, $71 \%$ Caucasians). The study was presented as an investigation of the validity of performance appraisal processes in organizations. Participants were randomly presented with the performance appraisal for one of two individuals in a midsized firm. The performance appraisals included performance ratings along six dimensions, on a scale from 1 (poor) to 5 (excellent), and was modeled after materials used in prior research (Leslie, Manchester, Park, \& Mehng, 2012). Three of the 
dimensions signaled competence (e.g., "Secures relevant information and identifies possible causes of problems”) and three signaled warmth (e.g., "Demonstrates the ability and willingness to express opposing viewpoints tactfully”). The exceptional competence individual excelled on competence $(M=4.7)$ and was below the scale midpoint on warmth $(M=2.3)$. The exceptional warmth individual excelled on warmth $(M=4.7)$ and was below the scale midpoint on competence $(M=2.3)$. After reviewing the performance appraisal, participants evaluated the status of the individual (five items: high-status, respected, admired by others, high prestige, and highly regarded by others; $\alpha=.81)$ using a seven-point scale ( $1=$ strongly disagree, 7 = strongly agree). After a series of filler tasks that took 15 minutes to complete participants filled in the same IND/COL scale used in past studies (IND: $\alpha=.72$; COL: $\alpha=.78$ ).

To serve as manipulation checks, participants rated the individual in terms of competence (four items: competent, capable, intelligent and ambitious; $\alpha=.83$ ) and warmth (four items: interpersonally warm, good-natured, sincere, and trustworthy; $\alpha=.86)$. Finally, participants answered demographic questions and were debriefed.

\section{Results and Discussion}

Manipulation checks. We first assessed the extent to which participants perceived the target individuals in terms of warmth and competence as intended. ANOVAs conducted on the competence and warmth ratings confirmed that participants perceived the exceptional competence individual $(M=4.92)$ as being more competent than the exceptional warmth individual $(M=4.05, t(56)=3.50, p<.01)$, whereas they perceived the exceptional warmth individual $(M=4.77)$ as being warmer than the exceptional competence individual $(M=3.49$, $t(56)=5.34, p<.01)$. 
Scale Structure. We fit the data to a three factor model (IND, COL, and status) and found a reasonable fit $(\mathrm{CFI}=.90, \mathrm{RMSEA}=.07)$, which was better than the fit of a single factor model $\left(\mathrm{CFI}=.40, \mathrm{RMSEA}=.14, \Delta \chi^{2}=235, p<.001\right)$. Correlations among the study variables appear in Table 1.

Hypothesis testing. To test Hypotheses 5 and 6, we conducted hierarchical regression with status perceptions ( $\alpha=.94)$ as the dependent variable (see Table 3). The first regression model (Model 1) included the following predictors: (a) competence/warmth performance dummy (b) IND and COL (mean-centered), and (c) the demographic covariates of age, gender (dummy coded 1 = male) and ethnicity (dummy coded, 1 = Caucasians). The next regression (Model 2) incorporated the two-way interactions between the performance dummy and the IND and COL scores. The results yielded significant coefficients for the performance dummy $\times$ IND interaction $(b=1.01, t(49)=2.96, p<.01)$ and for the performance dummy $\times$ COL interaction $(b=-.97$, $t(49)=-2.88, p<.01)$. To interpret these effects, we conducted simple slope analyses. Consistent with Hypothesis 5, IND was positively related to perceptions of status for the exceptional competence individual $(b=.60, t(49)=2.40, p<.03$ ), but unrelated to perceptions of status for the exceptional warmth individual $(b=-.41, t(49)=-1.60$, $n s$; see Figure 3$)$. Consistent with Hypothesis 6, COL was positively related to perceptions of status for the exceptional warmth individual $(b=.68, t(49)=2.83, p<.01)$, but unrelated to perceptions of status for the exceptional competence individual ( $b=-.30, t=-1.20$, $n s$; see Figure 3).

[Insert Table 3 \& Figure 3 about here]

As an additional analysis, we compared the perceived status of the exceptionally competent versus exceptionally warm individual for evaluators who are high on individualism and collectivism. For evaluators high on individualism, the exceptionally competent (but low 
warmth) individual was ascribed more status than the exceptionally warm (but low competence) individual $(b=1.21, t(49)=3.01, p<.005)$, whereas the same was not true for evaluators low on individualism $(b=-.47, t(49)=-1.16, n s)$. Alternatively, for those high on collectivism the exceptionally competent (but low warmth) individual was ascribed the same amount of status as the exceptionally warm (but low competence) individual ( $b=-.61, t(49)=-1.50, n s$ ), whereas the same was not true for evaluators low on collectivism $(b=1.03, t(49)=2.60, p<.02)$.

Discussion. Study 3 provides further evidence for the potential workplace consequences of a cultural patterning in the association of competence and warmth with status. Consistent with Hypothesis 5, evaluators higher on individualism ascribed more status to an exceptionally competent (but not warm) individual than evaluators lower on individualism, but individualism was not related to the status ascribed to an exceptionally warm (but not competent) individual. Supporting Hypothesis 6, evaluators higher on collectivism ascribed more status to an exceptionally warm (but not competent) individual than evaluators lower on collectivism, but collectivism was unrelated to the status ascribed to an exceptionally competent (but not warm) individual. Consistent with the Study 2 findings, and with the notion that competence is valued in all cultures (Schwartz, 1990), additional analyses revealed that the exceptionally competent individual was ascribed higher status than the exceptionally warm individual among those high in individualism, whereas the exceptionally competent and exceptionally warm individuals were ascribed the same status among those high in collectivism.

Studies 1-3 support the proposed cultural pattern in the determinants of status, but are not without limitations. For example, Study 1 was correlational, allowing for the possibility that common method variance and reverse causation may provide alternative explanations, and Study 3 was scenario-based, thus raising questions regarding whether the results will generalize to real 
world situations. In addition, in Studies 1 and 3 we used the same measure of individualism and collectivism and assessed cultural orientations at the end of the main experimental session. Although a common practice in cultural research (e.g., Lalwani, et al., 2009; Torelli \& Shavitt, 2010), this procedure might have induced some unintended carry over effects and we cannot rule out reverse causation. Study 2 addressed some of these limitations by operationalizing cultural orientation using membership in different cultural groups, instead of an individual difference measure, and assessing behaviors individuals engaged in to attain status at work, although the behaviors were assessed via recall of past behaviors.

In light of these potential limitations, we conducted a fourth study to provide evidence that cultural differences in the determinants of status have implications for how members of real world, task-focused groups evaluate each other in real time. We also address methodological limitations of Studies 1-3 by (1) assessing cultural orientation several weeks prior to the other study measures, (2) using a different measure of cultural orientation, (3) and gathering the measures of interest at three points in time. Finally, Study 4 further substantiates the importance of cultural differences in the determinants of status by demonstrating that perceived status has consequences for performance evaluations — an important outcome in organizations.

\section{Study 4}

In Study 4 we investigate whether the proposed cultural patterning in the association of competence and warmth with status emerges in real world, task-focused groups by using participants engaged in a team-based class project that lasted for three-and-a-half months. At the end of the project, participants evaluated their teammates' contributions to the final product, which were used to determine course grades. Thus, Study 4 allowed us to test whether cultural differences in the determinants of status have implications for performance evaluations. 
Our general propositions state that individualism is positively related to the tendency to associate competence with status and collectivism is positively related to the tendency to associate warmth with status. We therefore expect that team members who are higher (versus lower) in individualism will be more likely to use perceived competence to ascribe status to their teammates. In contrast, team members who are higher (versus lower) in collectivism will be more likely to use perceived warmth to ascribe status to their teammates.

Hypothesis 7: Team members who are higher on individualism will use perceptions of a teammate's competence to ascribe status to that teammate to a greater extent than team members who are lower on individualism.

Hypothesis 8: Team members who are higher on collectivism will use perceptions of a teammate's warmth to ascribe status to that teammate to a greater extent than team members who are lower on collectivism.

Abundant evidence documents that perceived status, in turn, has numerous favorable consequences for outcomes including performance evaluations. According to status characteristics theory, status characteristics (e.g., competence, warmth) determine who attains high status because individuals expect group members who possess valued status characteristics will achieve strong performance in the future (e.g., Berger et al., 1980). Perceived status, in turn, sets in motion a self-fulfilling prophecy with regard to performance; as compared to low status individuals, high status individuals are given more opportunities to demonstrate strong performance and also receive more favorable evaluations of their performance, even when performance is equivalent (e.g., Berger, et al., 1980; Darley \& Gross, 1983; Magee \& Galinsky, 2008; Sutton \& Hargadon, 1996). Thus, individuals ascribe high status to others based on expectations regarding how they are likely to perform in the future and perceived status, in turn, 
positively relates to evaluations of actual performance. We therefore predict that the proposed interactions between individualism and competence and between collectivism and warmth will not only have a direct effect on perceived status, but also an indirect effect on performance evaluations, through perceived status. Specifically, we expect the magnitude of the indirect effect of competence on performance evaluations, through status, will increase with individualism and that the magnitude of the indirect effect of warmth on performance evaluations, through status, will increase with collectivism.

Hypothesis 9: The indirect effect of perceptions of a teammate's competence on evaluations of that teammate's performance, through perceived status, will be stronger for team members who are higher on individualism than for team members who are lower on individualism.

Hypothesis 10: The indirect effect of perceptions of a teammate's warmth on evaluations of that teammate's performance, through perceived status, will be stronger for team members who are higher on collectivism than for team members who are lower on collectivism.

\section{Method}

Sample and task. The participants included 68 college students enrolled in a senior-level course in business administration at a large Midwestern university (mean age $=22.4$ years, 42\% male, 94\% Caucasians, 99\% had working experience, mean working experience $=2.3$ years). ${ }^{5}$ The participants took part in an involved team-based project in groups of 4-6 individuals that lasted 14 weeks. The project in question required each team to devote 60-70 hours to completing

\footnotetext{
${ }^{5}$ These are aggregate demographics that came from a separate survey that was completed by the same participants at the beginning of the course (approximately one month prior to the study). To maintain anonymity in participants' peer evaluations, no demographic information that could help to identify the participant was collected in the main study. As a result, we did not have individual-level demographic data that could be included as control variables in the analyses.
} 
a business plan for a company. Each team submitted a report at the end of the course, which accounted for $50 \%$ of each student's final grade. The project required significant coordination and interaction among group members and involved different activities (e.g., designing and conducting market surveys, analyzing primary data, gathering secondary data, devising alternative courses of actions for the company, writing and presenting a report). Due to the interdependent nature of the project, each team member was required to evaluate each teammate’s contribution to the project and peer evaluations were used by the instructor to determine students’ grades.

Measures. Three weeks prior to the last class participants completed an IND and COL measure as part of an in-class exercise ostensibly unrelated to the team project. We assessed cultural orientation with Singelis’ (1994) self-construal scale, which measures the independent self-construal associated with individualism (12-items: e.g., "Being able to take care of myself is a primary concern for me,” "I enjoy being unique and different from others in many respects;” $\alpha$ $=.70$ ), and the interdependent self-construal associated with collectivism (12-items: e.g., "It is important for me to maintain harmony within my group," "I often have the feeling that my relationships with others are more important than my own accomplishments;” $\alpha=.75$ ) using a seven-point scale (1 = Strongly disagree, 7 = Strongly agree $)$.

Participants anonymously submitted peer evaluations of their teammates (perceived competence, warmth, status, and performance) at two points in time. One week before the end of the class (and two weeks after the IND/COL scores were collected) participants evaluated each of their teammates in terms of competence (two items; “This group member is competent/capable;” $\alpha=.92$ ), warmth (two items; “This group member is good-natured/sincere,” $\alpha=.91$ ), and status (one item; “This group member is highly regarded by others in the group”) 
using a scale that ranged from " 1 = Strongly disagree” to "7 = Strongly agree.” The evaluations were conducted outside of class using an online form and participants were not aware of how they were evaluated by their teammates. On the last day of class (one week after completing the competence, warmth, and status measures and three weeks after completing the IND/COL measure) participants evaluated each teammate's performance on the project using a scale that ranged from 0-25. They wrote each teammate's performance appraisal on a piece of paper and deposited it in an envelope to guarantee that peer performance appraisals remained confidential. Participants submitted 248 complete evaluations (i.e. each of the 68 participants evaluated on average 3.6 teammates).

\section{Results and Discussion}

Status ratings. Correlations among the Study 4 variables appear in Table $1 .^{6}$ To test Hypotheses 7 and 8, we fit status perceptions to a multi-level linear model with the competence and warmth ratings as level-1 predictors, IND and COL as level-2 predictors, and the competence by IND and warmth by COL cross-level interactions. The model can be described as follows: status rating $=(\gamma 00+u 0)+(\gamma 10)$ competence $+(\gamma 20)$ warmth $+(\gamma 01)$ IND $+(\gamma 02) \mathrm{COL}+$ $(\gamma 11)$ competence $\times$ IND $+(\gamma 21)$ warmth $\times$ COL $+u 1+u 2+\mathrm{r}($ see Table 4$)$.

As depicted in Table 4 (Model 1), both the competence by IND $(\gamma=.42, t=2.37, p<.05)$ and warmth by COL $(\gamma=.27, t=2.26, p<.05)$ interactions were significant. To interpret these interactions, we graphed the interactions and conducted simple slope analyses at one standard deviation above and below the mean of IND and COL (Preacher, Curran, \& Bauer, 2006). In

\footnotetext{
${ }^{6}$ We lacked sufficient power to conduct a full CFA on the data to assess the fit of a six-factor structure (competence, warmth, individualism, collectivism, status rating, and performance evaluation) due to the use of 1-item and 2-item measures and the relatively small number of participants $(N=68)$; however, we conducted independent analyses to assess the discriminant validity of competence and warmth, as well as that of individualism and collectivism. A onefactor structure including all four competence and warmth items fit the data significantly worse than a two-factor structure that distinguished between competence and warmth $\left(\Delta \chi^{2}=212.3, p<.001\right)$. Similarly, a one-factor structure including all the individualism and collectivism items fit the data significantly worse than a two-factor structure that distinguished between individualism and collectivism $\left(\Delta \chi^{2}=52.53, p<.001\right)$.
} 
support of Hypothesis 7, Figure 4a reveals that the status-competence relationship was stronger for higher-IND participants $(\gamma=1.07, s e=.21, t(66)=5.00, p<.01)$ than for lower-IND participants $(\gamma=.48, s e=.19, t(66)=2.56, p<.02)$. The significant competence by IND interaction term indicates that the two slopes significantly differed from one another, although both slopes were significantly different from zero. In support of Hypothesis 8, Figure 4b reveals that the status-warmth relationship was stronger for higher-COL participants $(\gamma=1.02$, se $=.16$, $t(66)=6.20, p<.0001)$ than for lower-COL participants $(\gamma=.64$, se $=.15, t(66)=4.32, p<.01)$. The significant warmth by COL interaction term indicates that the two slopes significantly differed from one another, although both slopes were significantly different from zero.

[Insert Table 4 \& Figure 4 about here]

Performance evaluations. To test Hypotheses 9 and 10, we conducted mediated moderation analyses (Muller, Judd, \& Yzerbyt, 2005) to examine first stage moderated mediation (Edwards \& Lambert, 2007). First, we fit the performance evaluation measure to the same multi-level linear model estimated for status perceptions (see Table 4, Model 2). The warmth by collectivism interaction predicted performance evaluations $(\gamma=.95, t=2.79, p<.01)$, but the competence by individualism interaction did not $(\gamma=.48, t=.80, n s)$. A direct effect on performance evaluations, however, is not a necessary condition for establishing mediation (i.e. indirect effects; cf. Shrout \& Bolger, 2002). Next, we estimated a second mixed linear model adding status perceptions, the status perception by IND interaction, and the status perceptions by COL interaction as predictors (Model 3). The competence by individualism interaction remained non-significant $(\gamma=-.12, t=-.30, n s)$ and the warmth by collectivism interaction remained significant $(\gamma=.86, t=2.07, p<.05)$, but was reduced in magnitude. More importantly, status 
was positively related to performance evaluations $(\gamma=.97, t=6.44, p<.01)$, after controlling for IND/COL, competence/warmth, and the interactions.

The indirect effects were estimated as the product of the effect of competence/warmth on perceived status and the effect of perceived status on performance evaluations (after controlling for competence/warmth, IND/COL, and their interaction), calculated separately for higher and lower levels of IND/COL (see Muller, et al., 2005, for detailed formulas). We assessed the significance of the indirect effects using bootstrapping to calculate confidence intervals (CIs) with the MODMED macro (Model 5) provided in Preacher, Rucker, and Hayes (2007).

Figure 5 depicts the model for the indirect effects of perceived competence on performance evaluations, through status, at lower and higher levels of IND. For higher-IND participants, perceived competence was positively related to perceived status $(\gamma=1.07, p<.01)$ and perceived status was positively related to performance evaluations $(\gamma=1.38, p<.01)$. Moreover, the product of these two effects was also significant, indicating that competence had a significant indirect effect on performance evaluations, through status, for higher-IND participants (indirect effect $=1.48, \mathrm{CI}=.96$ to 1.99 ). In contrast, for lower-IND participants, although competence was positively related to status $(\gamma=.48, p<.02)$ and status was positively related to performance evaluations $(\gamma=.56, p<.05)$, the indirect effect of competence on performance evaluations, through status, did not reach significance (indirect effect $=.27$, CI $=-.06$ to .60 ). Moreover, the confidence intervals for the indirect effects among those higher versus lower in individualism did not overlap. These results indicate that the indirect effect of competence on performance evaluations, through status, was stronger for individuals higher (versus lower) on individualism and supports Hypothesis 9. 
Figure 6 depicts the model for the indirect effects of perceived warmth on performance evaluation, through status, at lower and higher levels of COL. For higher-COL participants, perceived warmth was positively related to perceived status $(\gamma=1.02, p<.001)$ and perceived status was positively related to performance evaluations $(\gamma=.84, p<.02)$. Moreover, the product of these two effects was significant, indicating that warmth had a significant indirect effect on performance evaluations, through status, for higher-COL participations (indirect effect $=.86$, CI $=.39$ to 1.33$)$. For lower-COL participants, warmth was positively related to status $(\gamma=.64, p<$ $.001)$, status was positively related to performance evaluations $(\gamma=1.09, p<.01)$, and the indirect effect of warmth on performance evaluations, through status, was significant (indirect effect $=.69, \mathrm{CI}=.42$ to .96$)$. Although the two confidence intervals for the indirect effects at high and low levels of COL partially overlapped, the ratio of the indirect effect to the total effect (a measure of effect size, Preacher \& Kelley, 2011) for higher-COL participants $\left(\mathrm{P}_{\mathrm{M}}=.66\right)$ was larger than that for lower-COL participants $\left(\mathrm{P}_{\mathrm{M}}=.26\right)$. Although results are in the expected direction, they fail to support Hypothesis 10.

[Insert Figure 6 about here]

Discussion. Study 4 demonstrates a cultural patterning in the tendency to use perceptions of competence and warmth to ascribe status and evaluate performance in real world interdependent groups. Team members who were higher (versus lower) on individualism were more likely to ascribe status to teammates based on perceived competence (Hypothesis 7), and the indirect effect of perceived competence on performance evaluations, through status, was stronger among participants higher (versus lower) in individualism (Hypothesis 9). In contrast, team members who were higher (versus lower) on collectivism were more likely to ascribe status to teammates based on perceived warmth (Hypothesis 8). The indirect effect of perceived 
warmth on performance evaluations, through status, did not differ significantly for participants higher (versus lower) in collectivism, although the effect was in the expected direction. These effects emerged using real-world, on-going teams involved in an interdependent project that required actions commonly undertaken by business professionals. Moreover, just as performance appraisals affect valued outcomes in work organizations (e.g., promotions, salary), the performance appraisal measure we used affected an outcome valued to the study participantscourse grades. Study 4 therefore supports the proposed cultural pattern in the determinants of status in a context with high psychological realism and suggests that our findings likely generalize to other business settings.

Although the effect of competence on status was stronger among individuals higher (versus lower) in individualism, competence was positively related to status for both groups, which is consistent with evidence that competence and individual achievement are universally valued (Schwartz, 1990). In addition, although the effect of warmth on status was stronger among individuals higher (versus lower) in collectivism, warmth was positively related to status for both groups. This is also not particularly surprising, given that the team project required coordination among team members and prior work substantiates that warmth is a status characteristic among individuals engaged in interdependent tasks (Fragale, 2006). At the same time, the present research also extends prior findings by demonstrating that cultural orientation is a meaningful source of variation in the characteristics individuals associate with status, even among individuals engaged in the same task as part of interdependent groups.

In spite of its many strengths, Study 4 was correlational. To reduce concerns regarding reverse causality and common method variance we measured individualism and collectivism several weeks prior to measuring competence, warmth, and status, which were measured several 
weeks prior to performance evaluations. Notably, competence, warmth and status were measured at the same time; however, we predicted and found that the effect of competence and warmth on status was moderated by cultural orientation. Empirical research demonstrates that common method variance reduces power for detecting interactions (Siemsen, Roth, \& Oliveira, 2009); it is therefore unlikely that common method variance provides a plausible alternative explanation for our findings.

\section{General Discussion}

The present research documents a cultural patterning in the determinants of status. Specifically, we integrated status characteristics theory with the literature on individualism and collectivism and proposed that the association between competence and status increases with individualism, whereas the association between warmth and status increases with collectivism. The proposed cultural pattern emerged in four studies that used a variety of methodologies. Specifically, cultural orientation influenced the extent to which people view high status individuals as competent and warm (Study 1), engage in behaviors that demonstrate competence and warmth to attain status at work (Study 2), view others' competence and warmth behaviors as signals of status (Study 3), and use competence and warmth when ascribing status to their teammates, and in turn evaluating their performance, when working on an interdependent task (Study 4). Across studies we operationalized cultural orientation using two different individual difference measures of individualism and collectivism and by sampling individuals from cultural groups known to vary in cultural orientation. Likewise, our dependent variables of interest included judgments of others (i.e. competence, warmth, and status; Studies 1 \& 3), recall of past workplace behaviors (Study 2), and evaluations of others’ performance that had concrete consequences (Study 4). This multi-method approach for demonstrating cultural effects attests to 
the validity of the findings (cf. Chiu \& Hong, 2006; Lalwani, Shavitt, \& Johnson, 2006; Torelli \& Shavitt, 2010).

\section{Implications for Theory and Practice}

The present research offers a number of contributions to existing theory and research.

First, by uncovering cultural differences in the determinants of status, our findings help to identify the type of behaviors and characteristics that facilitate status attainment in organizations and other task-focused groups. A large body of research on social hierarchies in general, and status hierarchies in particular, has begun to emerge in the organizational sciences (e.g., Magee \& Galinsky, 2008). Yet little research has investigated cultural contingencies in status attainment, as evidenced by the exclusion of status research from a recent review of the crosscultural organizational behavior literature (Gelfand, Erez, \& Aycan, 2007). This paucity of research is particularly striking given how central status differentials are for defining the cultural dimension of power distance - the first cultural dimension emerging from Hofstede’s (1980) seminal work. The lack of research on culture and status attainment is also surprising in view of extant research documenting cultural contingencies in leadership preferences and styles for which notions of status are consequential (e.g., House et al., 2006). We therefore help to fill this gap by substantiating that status is an important topic within the literature on culture and organizational behavior.

Second, our research contributes to status characteristics theory. Although empirical work has largely focused on perceived competence as the key determinant of status (cf. Berger, et al., 1980; Magee \& Galinsky, 2008), status characteristics theory posits that status characteristics may differ across settings and thus allows for the possibility of variation in the determinants of status. Consistent with this notion, past research has shown that the determinants of status are 
dependent on task type; a speech style that conveyed competence led to status among individuals working on an independent task, whereas a speech style that conveyed warmth led to status among individuals working on a task that required coordination (Fragale, 2006). Our theory and findings advance research on status characteristics theory by demonstrating that valued status characteristics vary not only with the setting (i.e. task type), but also as a function of individual differences in cultural orientation. Specifically, even among individuals involved in an interdependent team project (Study 4), team members’ differed in the extent to which they associated competence and warmth with status, as a function of their cultural orientation.

Third, our findings have implications for other theories of the importance of competence and warmth as fundamental dimensions of person perception. For example, research on the stereotype content model (e.g., Cuddy, et al., 2009; Fiske, et al., 2002) indicates that perceptions of status are positively related to competence-based stereotypes, whereas perceptions of competitiveness are negatively related to warmth-based stereotypes. The stereotype content model has received support in a variety of cultural contexts (Cuddy, et al., 2009), suggesting that the relationship between competence and status may be pancultural (i.e. hold true both for individualists and collectivists). Consistent with this conclusion, we found that both individualists and collectivists associate competence with status. At the same time, our findings suggest that the stereotype content model may be culturally contingent, such that the competence-status relationship is stronger among individuals from cultures that are higher (versus lower) on individualism, and that warmth is also associated with status among individuals from collectivistic cultures.

Fourth, our research has implications for schema and attribution theories. Specifically, culture influences the schema — or cognitive structures and processes-individuals use to 
organize information and make attributions about others (Markus \& Kitayama, 1991; Nisbett, 2003). For example, individualists tend to have a self-centered power schema that includes beliefs, attitudes, and goals that are relevant for the advancement of one's personal agenda, whereas collectivists tend to have an other-centered power-schema that includes cognitions that are relevant for helping others (Torelli \& Shavitt, 2010). Likewise, research on culturally-based implicit theories of leadership demonstrates that collectivists' schema for the definition of a good leader are more likely to include team-oriented behaviors than individualists’ schema (e.g., House et al., 2005). Our findings similarly point to cultural differences in the schemas individuals use to attribute status to others, such that individualism increases the tendency to apply a competence-based schema, whereas collectivism increases the tendency to apply a warmth-based schema. Thinking about our results in terms of the application of cultural schemas for attributing status to others suggests that such schemas might not only vary with the perceiver's cultural orientation, but also with the target's orientation. This may help to explain why women, who are typically stereotyped as interdependent, need to display competence and warmth to influence others whereas men, who are typically stereotyped as independent, need to display competence alone (Carli, LaFleur, \& Loeber, 1995).

Fifth, our research has the potential to add further clarity to related findings in the crosscultural organizational behavior literature, including social influence. For example, one study found that U.S. Americans were less likely than Polish individuals to comply with a request from a leader who lacked competence, whereas Polish individuals were less likely than U.S. Americans to comply with a request from a leader who lacked relational skills (Wosinska, et al., 2009; see Leslie \& Gelfand, 2011 for a reiew of simlar findings). The authors suggest that this finding may be attributable to differences in individualism and collectivism, but do not provide 
direct evidence for this assertion. Given that influence can be a consequence of status (Winter, 1973), our theory and findings suggest that cultural differences in the tendency to associate competence and warmth with status may explain why the leaders in this study were differentially influential.

Finally, the present research also has potential implications for managing cultural diversity at work, which is becoming increasingly important due to trends such as the growing number of Hispanic individuals in the U.S. workforce (Erickson, Falzon, Mishra, \& Mishra, 2012). For example, our findings suggest that an individual who is relatively high in collectivism (e.g., a Hispanic U.S. American) may engage in warmth behaviors at work to attain status (Study 2). However, if the employee has a manager who is relatively high in individualism (e.g., a White U.S. American), the manager may not interpret the employee's warmth behaviors as a signal of status (Study 3). Although we did not investigate such effects directly, such a mismatch may lead to frustration, a lack of commitment, and perceptions of discrimination on the part of the employee, which could promote turnover. Given that workplace diversity has the potential to enhance organizational effectiveness, yet U.S. organizations have not been particularly successful at retaining and growing a culturally diverse workforce (Cox \& Blake, 1991), our findings suggest that it may be in the best interest of organizations to foster greater awareness of cultural differences in the determinants of status, for example by providing cross-cultural training.

\section{Limitations and Future Research}

As with all research, the present studies are not without limitations. For example, the samples used in two of our four studies consisted of undergraduate students who have limited work experience. It is important to note, however, that prior studies of culture find similar results 
using samples of students and adults (e.g., Gelfand, et al., 2011), and that one of the undergraduate students samples comprised senior-level students with an average of 2.3 years of work experience. Moreover, in Study 2 the sample included both business graduate students and adults recruited from MTurk, who had significant work experience. The results of Study 2 were not moderated by the type of sample (graduate students versus MTurk), which further suggests that the use of student participants in some studies is not a significant limitation of our research.

Although we operationalized culture using both individual difference measures of cultural orientation and by sampling individuals from cultures known to vary in individualism and collectivism, we only sampled individuals from North and South America, which somewhat limits the generalizability of our effects to other cultures (e.g., Europe or Asia). For instance, the rules that prescribe how emotions are displayed vary among cultures that are relatively high in collectivism, such that outward displays of emotions are encouraged in Latin America and discouraged in Asia (Matsumoto, Kasri, \& Kooken, 1999). Given that emotional displays may increase perceptions of interpersonal warmth, future research should investigate whether the specific warmth-signaling behaviors associated with status differ in Latin versus Asian cultures. Research on this topic has the potential to advance existing research that investigates differential sensitivity to relational cues between individualists and collectivists (e.g., Sanchez-Burks, 2002; Sanchez-Burks, Lee, Choi, Nisbett, Zhao, \& Koo, 2003) by demonstrating that there may also be differences in individuals' reactions to different types of relational cues among collectivists from different cultures.

We operationalized culture as individual differences in cultural orientation and focused on individual-level outcomes (e.g., behaviors, evaluations of others); however, a cultural patterning in the determinants of status is also likely to be evident at higher levels of analysis. 
For example, future research could investigate whether there are systematic differences across countries in the human resource management practices used by organizations such that competence-related behaviors are more likely to be included in performance appraisals and used as the basis of workplace status and rewards in individualistic cultures, whereas warmth-related behaviors are more likely to be included in performance appraisals and used as the basis of workplace status and rewards in collectivistic cultures.

The process leading to the perception of status characteristics in certain behaviors may unfold through socio-cultural mechanisms such as the collective construction of situational meanings (Kitayama, Markus, Matsumoto, \& Norasakkunkit, 1997). Although we did not set out to investigate this process in the present studies, it stands to reason that cultural notions such as valued status characteristics are collectively defined and subjectively experienced in a way that fits the priorities of the culture. In this manner, the emergence of culturally shared definitions of many everyday behaviors should draw upon common frames of reference regarding status. Individualistic (collectivistic) cultures and their members may come to share an understanding of behaviors symbolizing competence (warmth) as affording status. Future research could investigate such a process by examining whether the same high-status individual is perceived differently across cultures in terms of possessing competence or warmth-related traits (e.g., competent vs. caring), or whether ambiguous behaviors (e.g., collaborating within a team to win a competition) are defined more in terms of competence or warmth in a given culture. Investigating these issues would contribute to the compelling cultural theory put forward by Kitayama and colleagues (Kitayama et al., 1997; Markus \& Kitayama, 1998).

Status and respect are important determinants of leader emergence in both organizations and politics (Rosar, Klein, \& Beckers, 2008). Thus, our findings offer interesting possibilities for 
research on leader emergence within multi-cultural organizations, as well as the drivers of electoral success in multi-cultural societies. For example, consistent with the individualistic orientation of the U.S., politicians in the U.S. often run for office on the basis of exhibiting competence when running businesses and organizations (e.g., Mitt Romney’s presidential campaign), and it is not uncommon to find highly competent businessman in public offices (e.g., Mike Bloomberg). This contrasts with the more caring image of politicians in Latin America, where powerful political leaders (or “caudillos”) are frequently idealized as benefactors whose primary goal is to protect helpless individuals (e.g., Hugo Chavez in Venezuela, Auyero, 2001). These observations are consistent with our findings and suggest that acquiring and maintaining a high political status in the more individualistic U.S. American culture might be closely linked to exhibiting competence, whereas doing so in more collectivist Latin American cultures might also depend on exhibiting warmth. Moreover, as the U.S. becomes increasingly diverse due to the influx of Latino and Asian immigrants, both who typically have more collectivistic cultural orientations, politicians may need to simultaneously demonstrate competence and warmth to earn the status necessary to be elected and successful in office, and the same may be true of leaders in culturally diverse organizations. Notably, such findings would be largely consistent with existing research on culture and leadership, indicating for example that collectivists are more likely than individualists to see other-oriented behaviors (e.g., team-building, participation, etc.) as exemplary of good leadership (House et al., 2005). Future research could expand on this finding, however, by demonstrating that perceived competence and warmth are parsimonious dimensions that explain why a number of specific behaviors are differentially associated with good leadership across cultures. 
Finally, we focused on individualism and collectivism, which are the most studied dimensions of culture in the organizational literature (cf. Gelfand, et al., 2007). Our findings substantiate the importance of individualism and collectivism for understanding the determinants of status, yet this is not the only aspect of culture that is likely relevant. For example, cultural differences in power distance-or the extent to which social hierarchies are seen as immutable in society—may also have implications for understanding status attainment. Future investigations of power distance and other cultural value differences will help enhance understanding of the relevance of status hierarchies for workplace processes.

\section{Conclusion}

Past research suggests that the characteristics associated with status attainment may be pancultural, by demonstrating that perceptions of competence are universally positively associated with the status of individuals and groups (Cuddy, et al., 2009). Yet status is granted based on characteristics that are valued because they enhance performance (e.g., Berger, et al., 1980), and decades of research demonstrate that valued social characteristics linked to performance vary with cultural differences in individualism and collectivism (Hofstede, 2001; House, et al., 2005), which suggests that individuals with different cultural orientations may use varied standards for granting status. The present research demonstrates that the association between competence and status increases with individualism, whereas the association between warmth and status increases with collectivism, and thus provides a more nuanced understanding of the determinants of status. In an era of increasing globalization and cultural diversity, these findings have important implications for successfully managing cultural differences at work. 


\section{References}

Alis, A. (1988). A cross-cultural perspective of managerial work value systems. In R. N. Farmer \& E. G. McGlowen (Eds.), Advances in international comparative management. Greenwich, CT: JAI Press.

Anderson, C., \& Kilduff, G. J. (2009a). The pursuit of status in social groups. Current Directions in Psychological Science, 18, 95-298.

Anderson, C., \& Kilduff, G. J. (2009b). Why do dominant personalities attain influence in faceto-face groups? The competence-signaling effects of trait dominance. Journal of Personality and Social Psychology, 96, 491-503.

Anderson, C., Spataro, S. E., \& Flynn, F. J. (2008). Personality and organizational culture as determinants of influence. Journal of Applied Psychology, 93, 702-710.

Asch, S. (1946). Forming impressions of personality. The Journal of Abnormal and Social Psychology, 41, 258-290.

Auyero, J. (2001). Poor people's politics: Peronist survival networks and the legacy of Evita. Durham, NC: Duke University Press.

Bakan, D. (1966). The duality of human existence. Chicago: Rand McNally.

Bentler, P. M. (1995). EQS structural equations program manual. Encino, Calif.: Multivariate Software.

Berger, J., Cohen, B. P., \& Zelditch, M. (1972). Status characteristics and social interaction. American Sociological Review, 37, 241-255.

Berger, J., Rosenholtz, S. J., \& Zelditch, M. (1980). Status organizing processes. Annual Review of Sociology, 6, 479-508.

Blau, P. M. (1964). Exchange and power in social life. Transaction Publishers. 
Bowles, H. R., \& Gelfand, M. (2010). Status and the evaluation of workplace deviance. Psychological Science, 21, 49-54.

Brislin, R. W. (1970). Back-translation for cross-cultural research. Journal of Cross-Cultural Psychology, 1, 185-216.

Buhrmester, M., Kwang, T., \& Gosling, S. D. (2011). Amazon's Mechanical Turk. Perspectives on Psychological Science, 6, 3-5.

Carli, L. L., LaFleur, S. J., \& Loeber, C. C. (1995). Nonverbal behavior, gender, and influence. Journal of Personality \& Social Psychology, 68, 1030-1041.

Castellucci, F., \& Ertug, G. (2010). What's in it for them? Advantages of higher-status partners in exchange relationships. Academy of Management Journal, 53, 149-166.

Chen, Y.-R., Brockner, J., \& Greenberg, J. (2003). When is it "a pleasure to do business with you?" The effects of relative status, outcome favorability, and procedural fairness. Organizational Behavior and Human Decision Processes, 92, 1-21.

Chen, Y.-R., Brockner, J., \& Katz, T. (1998). Toward an explanation of cultural differences in in-group favoritism: The role of individual versus collective primacy. Journal of Personality and Social Psychology, 75, 1490-1502.

Chiu, C.-Y., \& Hong, Y.-Y. (2006). Social Psychology of Culture. New York: Psychology Press.

Christie, A. M., \& Barling, J. (2010). Beyond status: Relating status inequality to performance and health in teams. Journal of Applied Psychology, 95, 920-934.

Cox, T. H., \& Blake, S. (1991). Managing cultural diversity: Implications for organizational competitiveness. Academy of Management Executive, 5, 45-56.

Cuddy, A. J., Fiske, S. T., Kwan, V. S., Glick, P., Demoulin, S., Leyens, J.-P., Bond, M. H., Croizet, J.-C., Ellemers, N., Sleebos, E., Htun, T. T., Kim, H.-J., Maio, G., Perry, J., 
Petkova, K., Todorov, V., Rodriguez-Bailon, R., Morales, E., Moya, M., Palacios, M., Smith, V., Perez, R., Vala, J., \& Ziegler, R. (2009). Stereotype content model across cultures: Towards universal similarities and some differences. British Journal of Social Psychology, 48, 1-33.

Darley, J. M., \& Gross, P. H. (1983). A hypothesis-confirming bias in labeling effects. Journal of Personality and Social Psychology, 44, 20-33.

Deci, E.L., \& Ryan, R.M. (1987). The support of autonomy and the control of behavior. Journal of Personality and Social Psychology, 53, 1024-1037.

Durkheim, É. (1997). The division of labor in society (W. D. Halls, Trans.). New York: Free Press.

Edwards, J. R., \& Lambert, L. S. (2007). Methods for integrating moderation and mediation: a general analytical framework using moderated path analysis.Psychological Methods, 12, $1-22$.

Erickson, S., Falzon, R., Mishra, J., \& Mishra, B. (2012). The rising Hispanic workforce. Advances In Managemen, 5, 7-14.

Ferris, G. R., \& Tredaway, D. C. (2008). Cultural diversity and performance appraisal systems. In D. L. Stone \& E. F. Stone-Romero (Eds.), The influence of culture on human resource management processes and practices. New York: Taylor \& Francis.

Fiske, S. T., Cuddy, A. J., Glick, P., \& Xu, J. (2002). A model of (often mixed) stereotype content: Competence and warmth respectively follow from perceived status and competition. Journal of Personality and Social Psychology, 82, 878-902. 
Flynn, F. J. (2003). How much should I give and how often? The effects of generosity and frequency or favor exchange on social status and productivity. Academy of Management Journal, 46, 539-553.

Flynn, F. J., Reagans, R. E., Amanatullah, E. T., \& Ames, D. R. (2006). Helping one’s way to the top: Self-monitors achieve status by helping others and knowing who helps whom. Journal of Personality and Social Psychology, 91, 1123-1137.

Fragale, A. R. (2006). The power of powerless speech: The effects of speech style and task interdependence on status conferral. Organizational Behavior and Human Decision Processes, 101, 243-261.

Fragale, A. R., Rosen, B., Xu, C., \& Merideth, I. (2009). The higher they are, the harder they fall: The effects of wrongdoer status on observer punishment recommendations and intentionality. Organizational Behavior and Human Decision Processes, 108, 53-65.

Frank, R.H. (1985). Choosing the right pond: Human behavior and the quest for status. New York: Oxford University Press.

Gelfand, M. J., Erez, M., \& Aycan, Z. (2007). Cross-cultural organizational behavior. Annual Review of Psychology, 58, 479-514.

Gelfand, M. J., Raver, J. L., Nishii, L., Leslie, L. M., Lun, J., Lim, B. C., Duan, L., Almaliach, A., Ang, S., Arnadottir, J., Aycan, Z., Boehnke, K., Boski, P., Cabecinhas, R., Chan, D., Chhokar, J., D’Amato, A., Ferrer, M., Fischlmayr, I. C., Fischer, R., Fülöp, M., Georgas, J., Kashima, E. S., Kashima, Y., Kim, K., Lempereur, A., Marquez, P., Othman, R., Overlaet, B., Panagiotopoulou, P., Peltzer, K., Perez-Florizno, L. R., Ponomarenko, L., Realo, A., Schei, V., Schmitt, M., Smith, P. B., Soomro, N., Szabo, E., Taveesin, N., Toyama, M., Van de Vliert, E., Vohra, N., Ward, C., \& Yamaguchi, S. (2011). 
Differences between tight and loose cultures: A 33-nation study. Science, 332, 11001104.

Goldhamer, H., \& Shils, E. A. (1930). Types of power and status. American Journal of Sociology, 45, 171-182.

Heinke, M. S., \& Louis, W. R. (2009). Cultural background and individualistic-collectivistic values in relation to similarity, perspective taking, and empathy. Journal of Applied Social Psychology, 39, 2570-2590.

Hofstede, G. H. (1980). Culture's consequences: International differences in work-related values. Newbury Park: Sage.

Hofstede, G. H. (2001). Culture's consequences : comparing values, behaviors, institutions and organizations across nations. Thousand Oaks, Calif.: Sage.

House, R. J., Hanges, P. J., Javidan, M., Dorfman, P. W., \& Gupta, V. (2005). Culture, leadership, and organizations: The GLOBE study of 62 societies. Thousand Oaks, CA: Sage Publications.

Humphrey, R. (1985). How work roles influence perception: Structural-cognitive process and organizational behavior. American Sociological Review, 50, 242-252.

Judd, C. M., James-Hawkins, L., Yzerbyt, V., \& Kashima, Y. (2005). Fundamental dimensions of social judgment: Understanding the relations between judgments of competence and warmth. Journal of Personality and Social Psychology, 89, 899-913.

Kitayama, S., Markus, H. R., Matsumoto, H., \& Norasakkunkit, V. (1997). Individual and collective processes in the construction of the self: self-enhancement in the United States and self-criticism in Japan. Journal of Personality and Social Psychology, 72, 1245-1267. 
Lalwani, A. K. (2009). The distinct influence of cognitive busyness and need for closure on cultural differences in socially desirable responding. Journal of Consumer Research, 36, 305-316.

Lalwani, A. K., Shavitt, S., \& Johnson, T. (2006). What is the relation between cultural orientation and socially desirable responding? Journal of Personality and Social Psychology, 90, 165-178.

Lalwani, A. K., Shrum, L. J., \& Chiu, C.-Y. (2009). Motivated response styles: The role of cultural values, regulatory focus, and self-consciousness in socially desirable responding. Journal of Personality and Social Psychology, 96, 870-882.

Lehman, D. R., Chiu, C.-Y., \& Schaller, M. (2004). Psychology and culture. Annual Review of Psychology, 55, 689-714.

Leslie, L. M. \& Gelfand, M. J. (2011). The cultural psychology of social influence: Implications for organizational politics. In. G. R. Ferris \& D. C. Treadway (Eds.), Politics in organizations: Theory and research considerations (pp. 411-447). New York: Taylor Francis Publishing.

Leslie, L. M., Manchester, C. F., Park, T.-Y., \& Mehng, S. A. (2012). Flexible work practices: A source of career premiums or penalties? Academy of Management Journal, 55, 14071428.

Lount, R. B., Jr., \& Pettit, N. C. (2012). The social context of trust: The role of status. Organizational Behavior and Human Decision Processes, 117, 15-23.

Magee, J. C., \& Galinsky, A. D. (2008). Social hierarchy: The self-reinforcing nature of power and status. The Academy of Management Annals, 2, 351-398. 
Markus, H. R., \& Kitayama, S. (1991). Culture and the self: Implications for cognition, emotion, and motivation. Psychological Review, 98, 224-253.

Markus, H. R., \& Kitayama, S. (1998). The cultural psychology of personality.Journal of CrossCultural Psychology, 29, 63-87.

Marx, K. (1964). Karl Marx: Early writings (T. B. Bottomore, Trans.). New York: McGraw-Hill.

Matsumoto, D., Kasri, F., \& Kooken, K. (1999). American-Japanese cultural differences in judgements of expression intensity and subjective experience. Cognition and Emotion, 13, 201-218.

McClelland, D.C. (1975). Power: The inner experience. Oxford, UK: Irvington.

Muller, D., Judd, C. M., \& Yzerbyt, V. Y. (2005). When moderation is mediated and mediation is moderated. Journal of Personality and Social Psychology, 89, 852-863.

Nisbett, R. E. (2003). The geography of thought: How Asians and Westerners think differently ... and why. (2003), NY, US: Free Press.

Oyserman, D., Coon, H. M., \& Kemmelmeier, M. (2002). Rethinking individualism and collectivism: Evaluation of theoretical assumptions and meta-analyses. Psychological Bulletin, 128, 3-72.

Ozdemir, V. E., \& Hewett, K. (2010). The effect of collectivism on the importance of relationship quality and service quality for behavioral intentions: A cross-national and cross-contextual analysis. Journal of International Marketing, 18, 41-62.

Perretti, F., \& Negro, G. (2006). Filling empty seats: How status and organizational hierarchies affect exploration versus exploitation in team design. Academy of Management Journal, 49, $759-777$. 
Preacher, K. J., Curran, P. J., \& Bauer, D. J. (2006). Computational tools for probing interaction effects in multiple linear regression, multilevel modeling, and latent curve analysis. Journal of Educational and Behavioral Statistics, 31, 437-448.

Preacher, K. J., \& Kelley, K. (2011). Effect size measures for mediation models: Quantitative strategies for communicating indirect effects. Psychological Methods, 16, 93-115.

Preacher, K. J., Rucker, D. D., \& Hayes, A. F. (2007). Addressing moderated mediation hypotheses: Theory, methods, and prescriptions. Multivariate Behavioral Research, 42, $185-227$.

Ridgeway, C. L., \& Walker, H. A. (1995). Status structures. In K. S. Cook, G. A. Fine \& J. S. House (Eds.), Sociological perspectives on social psychology (pp. 281-310). Boston, MA: Allyn \& Bacon.

Rosar, U., Klein, M., \& Beckers, T. (2008). The frog pond beauty contest: Physical attractiveness and electoral success of the constituency candidates at the North RhineWestphalia state election of 2005. European Journal of Political Research, 47, 64-79.

Sanchez-Burks, J. (2002). Protestant relational ideology and (in) attention to relational cues in work settings. Journal of Personality and Social Psychology, 83, 919-929.

Sanchez-Burks, J., Lee, F., Choi, I., Nisbett, R., Zhao, S., \& Koo, J. (2003). Conversing across cultures: East-West communication styles in work and nonwork contexts. Journal of Personality and Social Psychology, 85, 363-372.

Sande, G. N., Ellard, J. H., \& Ross, M. (1986). Effect of arbitrarily assigned status labels on selfperceptions and social perceptions: The mere position effect. Journal of Personality and Social Psychology, 50, 684-689. 
Schwartz, S. H. (1990). Individualism-collectivism: Critique and proposed refinements. Journal of Cross-Cultural Psychology, 21, 139-157.

Shore, B. (2002). Taking culture seriously. Human Development, 45, 226-228.

Shrout, P. E., \& Bolger, N. (2002). Mediation in experimental and nonexperimental studies: New procedures and recommendations. Psychological Methods, 7, 422-445.

Siemsen, E., Roth, A., \& Oliveira, P. (2009). Common method bias in regression models with linear, quadratic, and interaction effects. Organizational Research Methods, 13, 456-476.

Singelis, T. M. (1994). The measurement of independent and interdependent self-construals. Personality and Social Psychology Bulletin, 20, 580-591.

Slater, P. E. (1955). Role differentiation in small groups. American Sociological Review, 20, 300-310.

Sperber, D. (1996). Explaining culture: A naturalistic approach. Massachusetts: Blackwell.

Stone, D. L., Stone-Romero, E. F., \& Lukaszewski, K. M. (2007). The impact of cultural values on the acceptance and effectiveness of human resource management policies and practices. Human Resource Management Review, 17, 152-165.

Sutton, R. I., \& Hargadon, A. (1996). Brainstorming groups in context: Effectiveness in a product design firm. Administrative Science Quarterly, 41, 685-718.

Tannenbaum, A.S., Kavcic, B., Rosner, M., Vianello, M., \& Wieser, G. (1974). ] Hierarchy in organizations. San Francisco, CA: Jossey-Bass.

Torelli, C. J., \& Shavitt, S. (2008). Culture and mental representations of power goals: Consequences for information processing. Advances in Consumer Research, 35, 194-197. Torelli, C. J., \& Shavitt, S. (2010). Culture and concepts of power. Journal of Personality and Social Psychology, 99, 703-723. 
Triandis, H. C. (1995). Individualism and collectivism. CO: Westview Press.

Triandis, H. C., \& Gelfand, M. J. (1998). Converging measurement of horizontal and vertical individualism and collectivism. Journal of Personality and Social Psychology, 74, 118128.

Van de Ven, A. H., Delbecq, A. L., \& Koenig Jr, R. (1976). Determinants of coordination modes within organizations. American Sociological Review, 322-338.

Van Der Vegt, G. S., Bunderson, J., \& Oosterhof, A. (2006). Expertness diversity and interpersonal helping in teams: Why those who need the most help end up getting the least. Academy of Management Journal, 49, 877-893.

Vandello, J. A., \& Cohen, D. (1999). Patterns of individualism and collectivism across the United States. Journal of Personality and Social Psychology, 77, 279-292.

Weber, M. (1946). From Max Weber: Essays in sociology (H. H. Gerth, \& C.W. Mills, Trans.). New York: Oxford University Press.

Webster, M., Jr., \& Driskell, J. E., Jr. (1978). Status generalization: A review and some new data. American Sociological Review, 43, 220-236.

Winter, D. G. (1973). The power motive. New York, NY, US: Free Press.

Wojciszke, B., Bazinska, R., \& Jaworski, M. (1998). On the dominance of moral categories in impression formation. Personality and Social Psychology Bulletin, 24, 1251-1263.

Wosinska, W., Cialdini, R. B., Petrova, P. K., Barrett, D. W., Gornik-Durose, M., Butner, J., \& Griskevicius, V. (2009). Resistance to deficient organizational authority: The impact of culture and connectedness in the workplace. Journal of Applied Social Psychology, 39, 834-851. 
Zelditch, M. (1968). Social status. In D. Sills (Ed.), International encyclopedia of the social sciences (pp. 250-257). New York, NY: Macmillan. 